\title{
A Comparative Study of the Incidence and Severity of Surgical Site Infection Following Emergency and Elective Abdominal Surgeries
}

\author{
Sriranjani K.S. ${ }^{1}$, Rajeshwara K.V. ${ }^{2}$ \\ ${ }^{1}$ Department of General Surgery, Mandya Institute of Medical Sciences, Mandya, Karnataka, India. \\ ${ }^{2}$ Department of General Surgery, Father Muller Medical College, Mangalore, Karnataka, India.
}

\section{ABSTRACT}

\section{BACKGROUND}

Surgical site infections (SSI) represent a significant hurdle in the recovery and return to normalcy of patients. When considering abdominal surgeries in particular, SSI and its complications have been identified as one of the most important causes for postoperative morbidity. Treatment of SSI's ideally begins with prevention and this can be done with the identification of risk factors. This allows for appropriate stratification and institution of steps to safeguard the patient against the development of SSI in the pre-surgical period. The objectives of the study were to compare the incidence, severity and microbiological profile of surgical site infections following emergency and elective abdominal surgeries.

\section{METHODS}

This study was a prospective observational study, conducted from December 2017 to May 2019 at Father Muller Medical College Hospital, Mangalore, among patients who underwent laparotomy (regardless of indication) in either an elective or emergency setting. Patients who had SSI were then stratified using the ASEPSIS wound scoring system and the Southampton wound assessment scale. The type of SSI was further documented in each patient. Other parameters such as duration of stay in the hospital, microbiological profile, interventions performed etc. were also recorded in the study.

\section{RESULTS}

150 patients were enrolled in the study (84 female and 66 male), 23 patients (incidence of $15.33 \%$ ) developed an SSI (7 elective cases and 16 emergency cases), whereas 127 did not. Of the organisms cultured, the most common was found to be coagulase negative staphylococcus (CoNS, 7 cases) followed by E. coli (4 cases).

\section{CONCLUSIONS}

The following factors were found to significantly contribute to the development of SSI - nature of the surgery, i.e. elective vs. emergency (P-value 0.040 ), class of wound ( $\mathrm{P}$ value 0.001 ), underlying malignancy (P-value 0.030 ) and a concomitant urinary tract infection (UTI) (P-value 0.045). The following factors were not found to contribute to the development of a SSI - sex of the patient (P-value 0.108), age of the patient (Pvalue 0.699), presence of diabetes mellitus (DM) (P-value 0.816), chronic kidney disease (CKD) (P-value 0.904) and acute respiratory infection (ARI) (P-value 0.909).

\section{KEY WORDS}

Abdomen, Laparotomy, Staphylococcus aureus, Surgical Site Infections, Wound
Corresponding Author: Dr. Rajeshwara K. V, Associate Professor, Department of General Surgery, Father Muller Medical College, Kankanady - 575002,

Mangalore, Karnataka, India.

E-mail: rajeshwarakv@gmail.com

DOI: 10.14260/jemds/2021/90

How to Cite This Article:

Sriranjani KS, Rajeshwara KV. A comparative study of the incidence and severity of surgical site infections following emergency and elective abdominal surgeries. J Evolution Med Dent Sci 2021;10(07):404-408, $10.14260 /$ jemds/2021/90

Submission 09-10-2020,

Peer Review 17-12-2020,

Acceptance 23-12-2020,

Published 15-02-2021.

Copyright (C) 2021 Sriranjani K.S. et al. This is an open access article distributed under Creative Commons Attribution License [Attribution 4.0 International (CC BY 4.0)] 


\section{BACKGROUND}

Surgical site infection (SSI) is defined by the Centre for Disease Control and Prevention as a wound infection that occurs within 30 days of an operative procedure or within a year if an implant is left in place and the infection is thought to be secondary to surgery. ${ }^{1}$ Surgical site infections (SSI) represent a significant hurdle in the recovery and return to normalcy of patients. While once considered a necessary evil, as famously described by Osler: "Except on few occasions, the patient appears to die from the body's response to infection rather than from it", 2 there has been a slow yet powerful paradigm shift towards early identification and appropriate treatment of these infections.

When considering abdominal surgeries in particular, SSI and its complications have been identified as one of the most important causes for postoperative morbidity. ${ }^{3}$ In an era dominated by Enhanced Recovery Programs ${ }^{4}$ and day care surgery, ${ }^{5}$ with the ultimate emphasis being on early return to function and minimising hospital stay, SSI's have emerged as a potent hurdle to the successful execution of these principles. Consideration of SSI begins with classifying surgeries and the types of these infections.

Surgical wounds are also classified based on the presumed magnitude of the bacterial load at the time of surgery6:-

- Class I clean wounds.

- Class II clean / contaminated wounds.

- Class III contaminated wounds.

- Class IV dirty wounds.

Treatment of SSI's ideally begin with prevention, and prevention in itself begins with the identification of risk factors. This allows for appropriate stratification and institution of steps to safeguard the patient against the development of SSI in the presurgical period. This study was therefore conducted with the intention to better understand the spectrum of surgeries fostering SSI's and correlating that data with the type and severity of infections encountered, so as to allow for future stratification and appropriate treatment of patients. The objectives of the study were to compare the incidence, severity and microbiological profile of surgical site infections following emergency and elective abdominal surgeries.

\section{METHODS}

This study was a prospective observational study, conducted from December 2017 to May 2019 in Father Muller Medical College Hospital, Mangalore. The study was done on those patients who consented for the study and signed a written informed consent. The study was initiated after obtaining ethical clearance from the institution's ethical clearance committee. The patients admitted to Father Muller Medical College Hospital from December 2017 to May 2019, who underwent laparotomy (regardless of indication) in either an elective or emergency setting, aged above 12 years were included in the study.

\section{Exclusion Criteria}

- Patients diagnosed to be immunocompromised and on steroid treatment.
- $\quad$ Patients below the age of 12 .

- Patients with prosthesis.

- Patients undergoing relaparotomy for any reason other than surgical site infections.

- Patients not willing to participate in the study.

\section{Method of Collection of Data}

Routine, daily postoperative assessment of the patient's general condition and local examination of the patient's laparotomy wound was done to assess for presence or absence of surgical site infection. Patients who had SSIs were then stratified using the ASEPSIS wound scoring system. ${ }^{7}$ and the Southampton wound assessment scale. ${ }^{8}$ The type of SSI was further documented in each patient. Other parameters such as duration of stay in the hospital, microbiological profile, interventions performed etc. were also recorded. Patients with SSI's were investigated with wound culture and sensitivity, complete haemogram, ultrasound abdomen and / or computed tomography (CT) abdomen, if required (depending on the severity of the infection). Renal and liver function tests were also done.

\section{Sample Size Estimation}

The sample size was determined using the formula:

$N=(Z \alpha+Z \beta) 2 \times p q \times 2 / d 2$

Where,

$\mathrm{N}=$ sample size, $\mathrm{p}=$ average of prevalence according to study, $\mathrm{q}=100-\mathrm{p}$

$\mathrm{Z} \alpha=\mathrm{Z}$ score of $\alpha$ error (i.e. 1.96 with an $\alpha$ error of $5 \%$ )

$\mathrm{Z} \beta=\mathrm{Z}$ score of $\beta$ error (i.e. 0.842 with $\beta$ error of $20 \%$ )

$\mathrm{D}=\mathrm{p} 1-\mathrm{p} 2$

A retrospective observational study done in tertiary care centre, conducted in the Department of General Surgery and in the Department of Obstetrics and Gynaecology in Bangalore over a period of 18 months stated that the overall surgical wound infection rate was $13.7 \%$ and the infection rate was more with emergency surgery $(25.2 \%)$ when compared to elective surgery (7.6 \%). ${ }^{9}$ So, substituting values, sample size would be 78.150 patients fulfilling the eligibility criteria, from Father Mullers Medical College Hospital, Mangalore during the proposed study period were included.

\section{Statistical Analysis}

Collected data was summarised by frequency and percentages. Comparison between the two groups with respect to various parameters was done using chi-square test. Level of significance was $5 \%$ and analysis was done using Statistical Package for the Social Sciences (SPSS)-23 software.

\section{RESULTS}

\section{Age}

Of the 150 subjects enrolled in the study, the age of the patients ranged from 12 years (minimum included age) to above 80 years of age) (mean age of 46.36 and standard deviation of 
17.10466), with the majority of patients clustering in the age group of 21 to 70 years, with an absolute majority being in the age group between 21 and 30 years of age. Only 3 patients were found to be above 80 years of age. This is depicted in Table 1.

\begin{tabular}{|ccc|}
\hline Age (in years) & No. of Patients & Valid Percent \\
$<20$ & 2 & 1.3 \\
$21-30$ & 33 & 22 \\
$31-40$ & 27 & 18 \\
$41-50$ & 26 & 17.3 \\
$51-60$ & 28 & 18.7 \\
$61-70$ & 21 & 14 \\
$71-80$ & 10 & 6.7 \\
$>80$ & 3 & 2 \\
Total & $\mathbf{1 5 0}$ & $\mathbf{1 0 0}$ \\
\hline Table 1. Age Distribution of Patients Enrolled in the Study \\
\hline
\end{tabular}

Type of Operative Procedure

As all laparotomies were considered, a wide distribution of cases was observed. The distribution of cases is highlighted in Table 2.

\begin{tabular}{|c|c|c|}
\hline Type of Surgery & No. of Patients & Valid Percent \\
\hline Adhesiolysis & 1 & 0.7 \\
\hline Anterior resection & 7 & 4.7 \\
\hline Appendicectomy & 34 & 22.7 \\
\hline Appendicular abscess & 3 & 2 \\
\hline APR & 2 & 1.3 \\
\hline CBD exploration & 1 & 0.7 \\
\hline Colostomy closure & 3 & 2 \\
\hline Cytoreduction & 4 & 2.7 \\
\hline Exploratory laparotomy & 21 & 14 \\
\hline Feeding Jejunostomy & 3 & 2 \\
\hline Gastrojejunostomy & 2 & 1.3 \\
\hline Hemicolectomy & 3 & 2 \\
\hline Ileostomy & 4 & 2.7 \\
\hline Incisional hernia & 1 & 0.7 \\
\hline Intestinal obstruction & 2 & 1.3 \\
\hline Left hemicolectomy & 3 & 2 \\
\hline LSCS & 13 & 8.7 \\
\hline Lumbar sympathectomy & 1 & 0.7 \\
\hline Myomectomy & 3 & 2 \\
\hline Obstructed femoral hernia & 1 & 0.7 \\
\hline Open cholecystectomy & 1 & 0.7 \\
\hline Ovarian cystectomy & 3 & 2 \\
\hline Hollow viscus perforation & 7 & 4.7 \\
\hline Radical cholecystectomy & 1 & 0.7 \\
\hline Radical cystectomy & 1 & 0.7 \\
\hline Resection and anastomosis & 6 & 4 \\
\hline Subtotal gastrectomy+ FJ & 1 & 0.7 \\
\hline $\mathrm{TAH}+\mathrm{BSO}$ & 10 & 6.7 \\
\hline TAH+BSO+PLND & 1 & 0.7 \\
\hline Trans hiatal esophagectomy & 2 & 2 \\
\hline Whipple procedure & 3 & 2 \\
\hline Total & 150 & 100 \\
\hline \multicolumn{3}{|c|}{$\begin{array}{l}\text { Table 2. Operative Procedures Performed, with the } \\
\text { Number of Patients Who Underwent Each Procedure }\end{array}$} \\
\hline
\end{tabular}

\begin{tabular}{|c|c|c|c|c|c|}
\hline \multicolumn{5}{|c|}{ Crosstab } & \multirow[b]{2}{*}{ P-Value $(<0.05$ sig $)$} \\
\hline & & No & Yes & Total & \\
\hline \multirow{4}{*}{$\begin{array}{l}\text { Emergency / } \\
\text { Elective }\end{array}$} & Count & 68 & 7 & 75 & \multirow{6}{*}{0.040} \\
\hline & $\begin{array}{l}\% \text { within } \\
\text { SSI }\end{array}$ & $54 \%$ & $30.4 \%$ & $50 \%$ & \\
\hline & Count & 59 & 16 & 75 & \\
\hline & $\begin{array}{l}\% \text { within } \\
\text { SSI }\end{array}$ & $46 \%$ & $69.6 \%$ & $50 \%$ & \\
\hline \multirow[b]{2}{*}{ Total } & Count & 126 & 23 & 150 & \\
\hline & $\begin{array}{c}\text { \% within } \\
\text { SSI }\end{array}$ & $\begin{array}{c}100 \\
\%\end{array}$ & $100 \%$ & $100 \%$ & \\
\hline \multicolumn{6}{|c|}{$\begin{array}{c}\text { Table 3. Comparison of Prevalence of SSI's } \\
\text { in Elective vs. Emergency Cases }\end{array}$} \\
\hline
\end{tabular}

Comparison of Prevalence of SSI's in Elective vs. Emergency Cases

The patients under emergency setting had a greater number of SSI when compared to elective surgery.

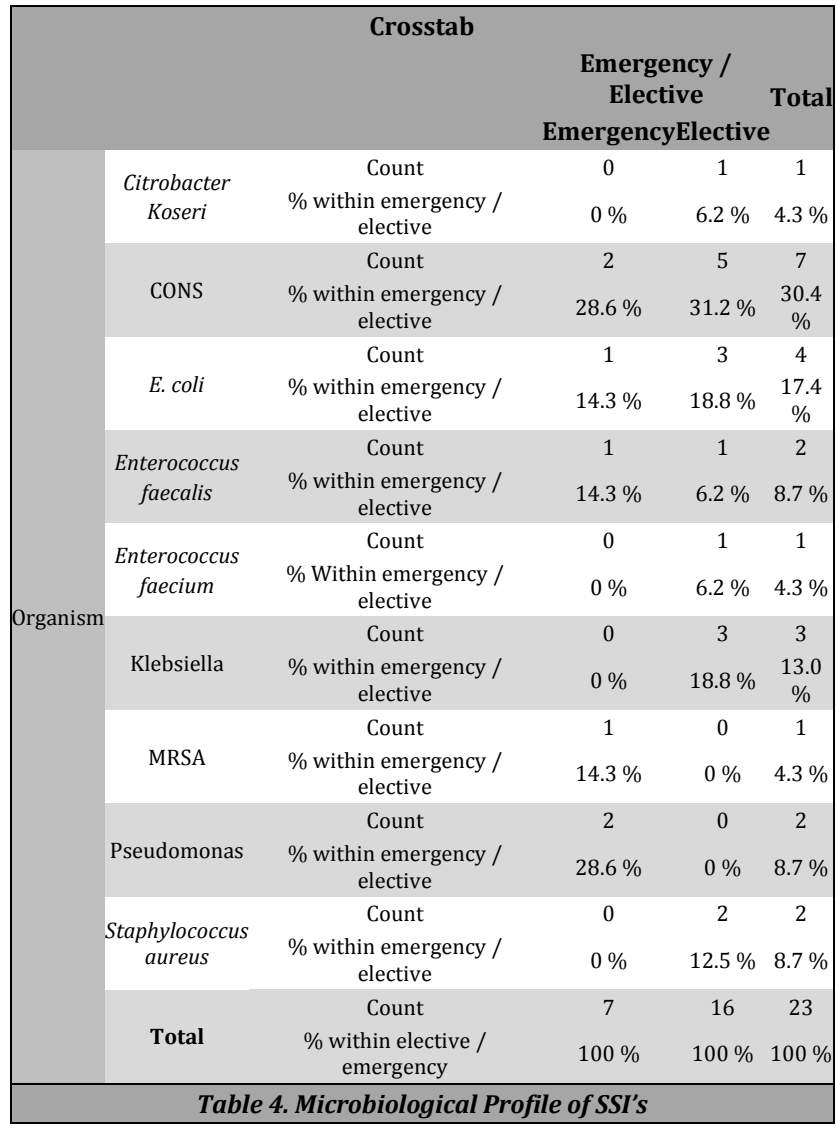

On doing culture and sensitivity study coagulase negative staphylococcus (CONS) is found to be predominant organism as shown in table 4 .

\begin{tabular}{|c|c|c|c|c|c|c|}
\hline \multicolumn{6}{|c|}{ Crosstab } & \multirow{3}{*}{$\begin{array}{l}\text { P-Value (< } \\
0.05 \text { is Sig) }\end{array}$} \\
\hline & & & \multicolumn{2}{|c|}{ SSI } & \multirow{2}{*}{ Total } & \\
\hline & & & No & Yes & & \\
\hline \multirow{4}{*}{ Diabetes } & \multirow[t]{2}{*}{ No } & Count & 92 & 17 & 109 & \multirow{6}{*}{0.816} \\
\hline & & $\%$ within SSI & $72.2 \%$ & $73.9 \%$ & $72.7 \%$ & \\
\hline & \multirow{2}{*}{ Yes } & Count & 35 & 6 & 41 & \\
\hline & & $\%$ within SSI & $27.8 \%$ & $26.1 \%$ & $27.3 \%$ & \\
\hline \multirow{2}{*}{\multicolumn{2}{|c|}{ Total }} & Count & 127 & 23 & 150 & \\
\hline & & $\%$ within SSI & $100 \%$ & $100 \%$ & $100 \%$ & \\
\hline \multicolumn{7}{|c|}{ Table 5. Association between Diabetes Mellitus and SSI } \\
\hline
\end{tabular}

Out of the 41 diabetic patients only 6 patients developed SSI as shown in table 5 .

\section{DISCUSSION}

A total of 150 patients were enrolled and followed up in the course of this study. The parameters that were considered have been detailed earlier in the article. While considering the age of the patients involved in the study, the vast majority clustered in the 20 - 60 age group (114 of 150 patients) as shown in Table 1. Most series describing SSIs show a similar clustering of patients, owing to numerous factors such as agerelated attrition (due to death or due to deference of surgery) and the relative incidence of surgical diseases requiring 
laparotomy in this age group. ${ }^{10}$ Age has been established as an independent risk factor in numerous studies.11,12 This can probably be explained by the clustering of patients in age groups that do not significantly alter the post-operative course of the patient, relative absence of patients of extremes of age and probably due to the better access and understanding of health care among the aged population.

A plethora of surgical procedures were performed on the patients enrolled in the study with the most common procedure being an appendicectomy ( 34 of 150 patients). This is advantageous, as it indicates the ability to apply the findings of this study over a broader category of surgical patients. A detailed list of the various procedures performed is tabulated in table 2. As described earlier, the nature of surgery performed plays a role in the development of SSI, however due to the smaller number of cases that developed an SSI and the wide range of procedures performed, a definitive correlation could not be ascertained.

All the patients enrolled in the study received prophylactic antibiotics. In most cases ( 44 of 150 cases) the antibiotic used was ceftriaxone with cefuroxime being the second most commonly used antibiotic (30 of 150 cases). This is in accordance with the hospital antibiotic protocol, which in turn is based on available literature that advocates the utilisation of cephalosporins as a prophylactic agent. ${ }^{13}$ Additionally, available recommendations also indicate switch over to other focussed antibiotics in conditions where there is high clinical suspicion of the offending organism. ${ }^{14}$ Subgroup analysis showed that a majority of patients ( 9 of 23) who subsequently went on to develop an SSI were administered ceftriaxone in the pre-operative period, likely indicating antibiotic resistance among organisms in the region under study due to local factors. This underscores the importance of regional factors in establishing protocols in the prevention and subsequent treatment of SSIs. Of the 150 patients studied, 23 patients developed an SSI, accounting for $15.3 \%$ of patients. The quoted incidence of SSI varies widely in available literature, with authors describing rates as low as $5 \% 15$ to $20 \%{ }^{16}$ and $55.56 \%, 17$ indicating that this study was within acceptable parameters. Of the various factors considered, the first factor was the nature of the surgery, i.e., elective or emergent. Of the 23 patients who went on to develop an SSI, 16 patients underwent surgery on an emergency basis, whereas, 7 patients had routinely scheduled elective procedures. A significant statistical difference was also observed (Table 3), thereby establishing that the nature of surgery (i.e. elective or emergency) also serves as a risk factor for the development of SSI. However, this study and comparative studies described earlier, ${ }^{18}$ clearly establish that the nature of surgery poses an inherent risk to the development of SSI's indicating that these patients warrant heightened vigilance and awareness.

The microbiological profiling of the SSIs showed that the most common organism cultured was coagulase negative staphylococcus (CONS) (7 of 23 cases), with E. coli being the second most common organism ( 4 of 23 cases). Most studies have shown that the most common organism cultured in SSIs are Staphylococcus aureus followed by coagulase-negative staphylococci CoNS, owing to the ubiquity of $S$. aureus as skin flora. ${ }^{19,20}$ However, as demonstrated in Table 3, only two cases of $S$. aureus were isolated in this study. The remainder of the organism spectrum was stable and comparable to available literature.
Diabetes mellitus as a risk factor for the development of SSI is well documented in the literature. ${ }^{21}$ The mechanisms involve immune dysfunction, poor circulation and atherosclerosis. Patients are also inherently more susceptible to antibiotic resistant strains such as methicillin-resistant Staphylococcus aureus (MRSA) and vancomycin resistant enterococci. Of the patients enrolled in this study, it was found that 41 of the 150 had pre-existing DM, only 6 of these patients developed an SSI. Correlation statistics did not show a significant difference. Therefore, DM was not a significant risk factor towards developing SSI.

\section{CONCLUSIONS}

While surgical site infections continue to be a major thorn in a surgeon's paw, analysis of risk factors, optimal management in the perioperative period and targeted therapy of established infections can significantly ease the burden. Elucidation of risk factors such as the nature of surgery performed (i.e., emergent vs. elective), underlying comorbidities, presence or absence of remote infections and the type of wound, allow for appropriate patient stratification and treatment of risk factors.

This study also demonstrates the changing nature of the microbiological flora implicated in SSI and the resultant antibiotic resistances, highlighting the regional and demographic distributions of SSIs. This allows for alteration of antibiotic protocols and emphasises the need for more regional and hospital-based surveillance programs.

In conclusion, the effective management of SSIs relies on a two pronged approach, consisting of risk factor management for prevention and appropriate therapy for established infection.

Data sharing statement provided by the authors is available with the full text of this article at jemds.com.

Financial or other competing interests: None.

Disclosure forms provided by the authors are available with the full text of this article at jemds.com.

\section{REFERENCES}

[1] Horan TC, Andrus M, Dudeck MA. CDC/NHSN surveillance definition of health care-associated infection and criteria for specific types of infections in the acute care setting. Am J Infect Control 2008;36(5):309-32.

[2] Ravenel MP. The life of sir William Osler. Am J Public Health 1925;15(10):904-6.

[3] Krukowski ZH, Matheson NA. Ten-year computerized audit of infection after abdominal surgery. Br J Surg 1988;75(9):857-61.

[4] Ljungqvist O, Scott M, Fearon KC. Enhanced recovery after surgery a review. JAMA Surg 2017;152(3):292-8.

[5] Shnaider I, Chung F. Outcomes in day surgery. Curr Opin Anaesthesiol 2006;19(6):622-9.

[6] Martone WJ, Nichols RL. Recognition, prevention, surveillance and management of surgical site infections: introduction to the problem and symposium overview. Clin Infect Dis 2001;33(Suppl 2):S67-8.

[7] Wilson APR, Sturridge MF, Treasure T, et al. A scoring method (ASEPSIS) for postoperative wound infections for 
use in clinical trials of antibiotic prophylaxis. Lancet 1986;1(8476):311-3.

[8] Tiwari S, Chauhan M, Shahapurkar VV, et al. Importance of southampton wound grading system in surgical site infection. J Evol Med Dent Sci 2014;3(20):5491-5.

[9] Satyanarayana V, Prashanth HV, Bhandare B, et al. Study of surgical site infections in abdominal surgeries. Journal of Clinical and Diagnostic Research 2011;5(5):935-9.

[10] Malone DL, Genuit T, Tracy JK, et al. Surgical site infections: reanalysis of risk factors. J Surg Res 2002;103(1):89-95.

[11] Golpanian S, Kassira W. Full-thickness skin graft. In: Operative dictations in plastic and reconstructive surgery. Springer International Publishing 2016: p. 199201.

[12] Harrop JS, Styliaras JC, Ooi YC, et al. Contributing factors to surgical site infections. J Am Acad Orthop Surg 2012;20(2):94-101.

[13] Prtak LE, Ridgway EJ. Prophylactic antibiotic surgery. Surgery 2009;27(10):431-4.

[14] Tovar JR, Badia JM. Prevention of surgical site infection in abdominal surgery. A critical review of the evidence. Cir Esp 2014;92(4):223-31.
[15] Pathak A, Saliba EA, Sharma S, et al. Incidence and factors associated with surgical site infections in a teaching hospital in Ujjain, India. Am J Infect Control 2014;42(1):e11-5.

[16] Santalla A, López-Criado MS, Ruiz MD, et al. Surgical site infection. Prevention and treatment. Clin Invest Ginecol Obstet 2007;34(5):189-96.

[17] Bandaru NR, Rao AR, Prasad KV, et al. A prospective study of postoperative wound infections in a teaching hospital of rural setup. J Clin Diagnostic Res 2012;6(7):1266-71.

[18] Sørensen LT, Hemmingsen U, Kallehave F, et al. Risk factors for tissue and wound complications in gastrointestinal surgery. Ann Surg 2005;241(4):654-8.

[19] Emori TG, Gaynes RP. An overview of nosocomial infections, including the role of the microbiology laboratory. Clin Microbiol Rev 1993;6(4):428-42.

[20] Schaberg DR, Culver DH, Gaynes RP. Major trends in the microbial etiology of nosocomial infection. Am J Med 1991;91(3B):72S-5.

[21] Dryden M, Baguneid M, Eckmann C, et al. Pathophysiology and burden of infection in patients with diabetes mellitus and peripheral vascular disease: focus on skin and softtissue infections. Clin Microbiol Infect 2015;21(Suppl 2):S27-32. 